\title{
Detection of Mycobacterium Tuberculosis IgM and IgG Antibodies and Associated Risk Factors Among Apparently Healthy Undergraduate Students of a Private University in South-West Nigeria
}

\author{
Seyi Samson Enitan ${ }^{1}$, Morenikeji Hannah Adeniyi ${ }^{1}$, Surajudeen Alim Junaid ${ }^{2}$, Ernest Chibuike Ohanu ${ }^{3}$, Nwachi \\ Idume Ogbonna ${ }^{4}$, Effiong Effiong Joseph ${ }^{1}$, Grace Eleojo Itodo ${ }^{5}$, Oluyemisi Ajike Adekunbi ${ }^{1}$, Joan Osamouyi \\ Odigie $^{1} \&$ Ayomide Ruth Olabanji ${ }^{1}$ \\ ${ }^{1}$ Department of Medical Laboratory Science, Babcock University, Ilishan-Remo, Nigeria \\ ${ }^{2}$ Department of Medical Laboratory Science, Federal University, Lafia, Nigeria \\ ${ }^{3}$ Department of Medical Laboratory Science, University of Calabar, Calabar, Nigeria \\ ${ }^{4}$ Department of Education, Medical Laboratory Science Council of Nigeria, FCT-Abuja, Nigeria \\ ${ }^{5}$ Department of Medical Microbiology, Federal Medical Centre, Lokoja, Nigeria \\ Correspondence: Seyi Samson Enitan, Department of Medical Laboratory Science, Babcock University, Ilishan- \\ Remo, Nigeria, Tel: 234-8065-483-761. E-mail: enitans@babcock.edu.ng
}

Received: December 11, 2021; Accepted: February 4, 2022; Published: February 12, 2022

The research is self-financed.

\begin{abstract}
Background: Infection with Mycobacterium tuberculosis (TB) is frequent among Nigerians. Many people are infected without realizing it (asymptomatic) and thus provide a risk of transmission to others. Not only will early treatment prevent TB complications, but it will also help to break the infection cycle in a community.
\end{abstract}

Objective: The study was conducted to determine the prevalence of Mycobacterium tuberculosis IgM and IgG antibodies and associated risk factors among apparently healthy undergraduate Students of Babcock University, Ilishan-Remo, Ogun State.

Methodology: The serum samples of 100 consenting participants were collected randomly and screened for TB antibodies using Aria TB IgG/IgM Combo Rapid Antibody Test Cassette (CTK Biotech Inc. Poway, CA 92064, USA). A structured questionnaire was administered to consenting students to obtain information on their bio-data (e.g, the age, sex, study level etc.), as well as clinical information regarding their health (History of TB, history of BCG vaccination, use of anti-TB medications, alcohol consumption, smoking habits etc.).

Results: The outcome of this study shows that $15(15 \%)$ out of the 100 participants screened, were positive for TB IgG antibody, while, only $1(1 \%)$ person was positive for TB IgM antibody. There was no significant association $(P>0.05)$ between percentage TB IgG positivity and the socio-demographic characteristics of the study participants (gender, age, study level and tribe), except for religion. The percentage of TB IgG positivity among the study participants was found to be significantly higher than of TB IgM positivity $(\mathrm{P}<0.05)$. None of the 15 participants who tested positive to TB IgG indicated any of the signs and symptoms (persistent cough, chest pain, nausea, fever, chills, loss of appetite, fatigue and night sweat) associated with TB), however the only person who tested positive for TB IgM indicated all, except night sweat. Identified risk factors associated with the occurrence of TB IgM include history of TB, lack of BCG vaccination, history of diabetes and physical unfitness.

Conclusion: The findings of this study show that asymptomatic and latent tuberculosis infection exists among the study participants, and that if left untreated, it will progress to active tuberculosis with all of its associated complications, including death. This emphasizes the importance of ongoing public health education, BCG vaccination, and periodic screening to detect asymptomatic cases in the study population in order to break the infection cycle.

Keywords: Mycobacterium tuberculosis, antibodies, risk factors, students, South-West Nigeria 


\section{Introduction}

Tuberculosis (TB) is one of the deadliest airborne infectious diseases in the world, affecting around two (2) billion people [1]. It is caused by the bacterium popularly called Mycobacterium tuberculosis. Usually, the predilection site of the organism is the lungs (Pulmonary tuberculosis), but infection can also spread to other organs of the body (disseminated tuberculosis) including the lymph glands, meninges, spleen, liver, kidneys, bone and joints. Infection of other organs causes a wide range of symptoms, and it can be fatal in many cases if not treated early [2].

Robert Koch, the Nobel Prize winner, first described Mycobacterium tuberculosis, also known as the "tubercle bacillus," in 1882. The organism is an obligate aerobe, non-motile, non-spore-forming, acid-fast bacillus that often appears beaded or unstained when stained with Gram stain. Its ability to produce stable mycolate complexes with aryl methane dyes (carbolfuchsin, auramine, and rhodamine) distinguishes it from all other mycobacteria [3].

Infection occurs when susceptible individuals inhale cough droplets (or dust particles containing tubercle bacilli) released from people with active TB infection when they either cough or sneeze. The virus travels largely as air droplets called aerosols which become lodged in the lung, forming an inflammatory lesion [4]. Tuberculosis, next to HIV/AIDS, is the second most common cause of death from infectious diseases and therefore remain a global public health issue with severe consequences [5]. According to the World Health Organization (WHO), Mycobacterium tuberculosis infects roughly one-third of the world's population, with the highest prevalence in Sub-Saharan Africa and about 1\% of the world's population becoming infected each year. In 2016, 10.4 million people became infected with TB and 1.6 million died as a result of the disease [6].

In latent tuberculosis infection, it is very rare for infected people to show any sign or symptom of TB. If left untreated, about one-tenth of such cases progresses to active tuberculosis infection, which kills more than half of those who are infected. Approximately $10 \%$ of patients with latent infection experience reactivation, half within the first year and the rest over the course of their lives. In general, 10-15 percent of those who are infected acquire active disease at some point later in life. A chronic cough characterized with the production of mucopurulent sputum with or without blood, fever, night sweats, fatigue, chest pain, anaemia and weight loss are all hallmark indications of active tuberculosis infection. Complications amongst others include TB pericarditis, pleurisy and sometimes lung collapse [6,7]. Immunocompromised individuals such as those suffering from HIV infection and cancer, those with history of TB infection in the last two years, including individuals who were not treated correctly for TB in the past, users of illicit drugs and alcoholics, as well as infants, young children, the elderly, and those with underlying conditions such as diabetes, hypertension, and liver and kidney failure, have been observed to be at a higher risk of contracting Mycobacterium tuberculosis [8].

Normally, radiology (commonly chest X-rays) is used to diagnose active TB. However, in latent tuberculosis infections, the detection is commonly done by tubulin skin testing or using Rapid test kits to look for the presence of IgM and IgG TB antibodies. In most developing nations, M. tuberculosis is cultured, identified, and subjected to susceptibility testing in a Reference Tuberculosis Laboratory to manage treatment failures, monitor multi-drug resistance, and identify various strains and variants of the organism. TB infection is treated with antibiotics such as isoniazid and rifampin, and treatment can last up to six (6) months or longer depending on the severity. This is due to the peculiarity of the surface chemistry of the cell wall of the organism (presence of mycolic acid), which slows or limits penetration of the anti-TB drugs $[9,10]$.

Mycobacterium tuberculosis infection is common among Nigerian populace. Many are infected without knowing (i.e., asymptomatic or symptom-free) and therefore constitute source of infection to others. Early detection will not only prevent complications associated with $\mathrm{TB}$, but will also assist to break the cycle of infection in a community. Due to the nature of the school environment, aerosols are easily spread among university students, especially during lectures in overcrowded classrooms without adequate cross-ventilation or during social gatherings such as music concerts and indoor sport activities in the absence of social distancing and wearing of face masking. These amongst others, increasing the chance and risk of exposure among university students. To the best of our knowledge, no research has been conducted to determine the sero-prevalence of Mycobacterium tuberculosis infection among undergraduate students of Babcock University, Ilishan-Remo, Ogun State. Furthermore, the risk factors related with the incidence of TB IgM and IgG antibodies among research participants must be identified. As a result of the scarcity of information in this area, this research is required. The aim of this study is to find out how common Mycobacterium tuberculosis IgM and IgG antibodies (as well as the risk factors that go along with them) are among Babcock University's seemingly healthy undergraduate students. 


\section{Method}

\subsection{Study Design}

This is a cross sectional descriptive study.

\subsection{Study Area}

The study area was Babcock University, Ilishan-Remo, a geographical region in Ogun state, Nigeria, with coordinates $6.8862^{\circ} \mathrm{N}, 3.7055^{\circ} \mathrm{E}$. The University comprises nine (9) schools all of which provide a variety of academic and professional programmes at the undergraduate and postgraduate levels, with a total student population of approximately twelve thousand $(12,000)$ students.

\subsection{Study Duration}

The research work was carried out within the period of a month (May, 2021).

\subsection{Study Population}

This cross-sectional institutional-based study was conducted among seemingly healthy Babcock University undergraduate students in Ilishan-Remo, Ogun State.

\subsection{Sample Size Calculation}

The sample size for the study was estimated using the formula described by Solomon et al. [2].

\section{$\mathbf{N}=\underline{\mathbf{Z}^{2} \mathbf{X} \mathbf{P}(\mathbf{1 - P})}$}

\section{$D^{2}$}

Where;

$\mathrm{N}=$ minimum sample size

$\mathrm{p}=$ prevalence

$\mathrm{D}=$ level of significance $(0.05)$

$\mathrm{Z}=$ Confidence interval (1.96)

For the calculation, a $95 \%$ confidence interval, a $\mathrm{P}$ value of 0.0667 , i.e., a prevalence rate of $6.67 \%$ for Mycobacterium tuberculosis among students from previous study by Chinedu et al., [11], and margin of error (d) set at 0.05 was used to determine the minimum sample size required. To minimize errors arising from the likelihood of non-compliance, 4 extra samples was added to the sample size.

$$
\begin{aligned}
& \mathbf{N}=\frac{\mathbf{Z}^{2} \mathbf{X ~ P ( 1 - P )}}{\mathbf{D}^{2}} \\
& Z=1.96 \\
& P=6.67 \%[11] \\
& \mathrm{N}=\frac{1.96^{2} \times 0.0667(1-0.0667)}{(0.05)^{2}} \\
& \mathrm{~N}=\frac{3.8416 \times 0.0667 \times 0.9333}{0.0025} \\
& \mathrm{~N}=\frac{0.2391}{0.0025} \\
& \mathrm{~N}=95.6575 \simeq 96
\end{aligned}
$$

Sample size is therefore $96+4=\mathbf{1 0 0}$

\subsection{Sample Size}

A total of 100 blood samples were taken from 100 Babcock University undergraduate students in Ilishan-Remo, Ikenne Local Government Area, Ogun State, Nigeria, who gave their consent.

\subsection{Sample Selection}

Twenty students i.e., 10 male students and 10 female students were selected randomly from 5 different schools 
namely; 1) Public and Allied Health (SPAH), 2) Babcock Business school (BBS), 3) School of Basic and Applied Sciences (SBAS), 4) Benjamin Carson's School of Medicine (BCSM), 5) School of Nursing (SN).

\subsection{Ethical Consideration}

Ethical clearance (with ethical registration number: BUHREC600/21) was obtained from Babcock University Health Research Ethics Committee (BUHREC) before the commencement of the study.

\subsection{Eligibility of Subjects}

\subsubsection{Inclusion Criteria}

Consenting apparently healthy undergraduate students was recruited for the study.

\subsubsection{Exclusion Criteria}

Postgraduate students were excluded from the study.

\subsection{Informed consent}

All participants gave their informed consent before being included in the study population. After being thoroughly informed about the objective and nature of the study, as well as the technique of sample collection, participants were needed to freely complete the consent form in their own handwriting and sign it as proof of willingness to supply samples for the test. They were given assurances that the requisite anonymity would be maintained.

\subsection{Data Collection}

Consenting students were given a structured questionnaire to collect information on their bio-data (e.g., age group, sex, study level), clinical and associated risk factors (alcohol consumption, smoking habits, medical history, family history, use of medications etc.).

\subsection{Sample Collection and Transportation}

Five $(5 \mathrm{ml})$ of venous blood samples was collected into plain bottles and was allowed to clot to get the sera from the patients.

\subsection{Specimen Storage}

The specimens were not preserved because they were needed to be processed as quickly as possible. Blood samples were allowed to coagulate for about an hour before being retracted and centrifuged at room temperature for 10 minutes at 3,500 rpm. The serum was immediately transferred to another clean sterile plain container and analyzed; alternatively, if a delay was expected, the serum was stored at $2-8^{0} \mathrm{C}$ for up to three days. The specimens were kept at a temperature below $-20^{\circ} \mathrm{C}$ for long-term storage. The frozen specimens were completely thawed and mixed before testing. Multiple freeze-thaw cycles were not performed on the sera. Frozen specimens were progressively warmed to room temperature and gently mixed before testing.

\subsection{Laboratory Analysis}

\subsubsection{Detection of Mycobacterium tuberculosis IgG and IgM antibodies}

Serum anti-M. tuberculosis (TB) IgG and IgM antibodies was detected using Aria TB IgG/IgM Combo Rapid Antibody Test Cassette (Figure 1) supplied by CTK Biotech, Inc., Poway, CA 92064, USA according to the manufacturer's instruction.

\subsubsection{Principle}

The TB IgG and IgM Test is a qualitative lateral flow chromatographic immunoassay for the detection and differentiation of Mycobacterium tuberculosis infection IgG and IgM in human blood, plasma and serum. The test cassette consists of three strips for IgG and IgM detection respectively and a control (C) line. A burgundy-colored conjugate pad containing (M. TB) antigens conjugated with colloidal gold (M. TB conjugates) and rabbit IgGGOLD is used to detect TB IgG and IgM. Two test brands ( $\mathrm{M}$ and $\mathrm{G}$ bands) and a control band are included on a nitrocellulose membrane strip ( $\mathrm{C}$ band). The $\mathrm{M}$ band is pre-coated with monoclonal anti-human IgM to detect IgM anti-M TB, the G band is pre-coated with reagents to detect IgG anti-M TB, and the C band is pre-coated with goat 
anti-rabbit IgG to detect IgG anti-M. TB.

The specimen travels by capillary action across the cassette when an adequate volume of test specimen is allotted into the sample well of the cassette. IgM anti- $M . T B$ if present in the specimen, binds to the $M$. TB conjugates. The pre-coated anti human IgM antibody on the membrane captures the immunocomplex forming a burgundycolored $\mathrm{M}$ line, indicating a $M . T B$ IgM positive test result. IgG anti- $M$. $T B$ if present in the specimen, binds to the $M$. $T B$ conjugates. The pre-coated reagents on the membrane captures the immunocomplex forming a burgundycolored $\mathrm{G}$ line, indicating a $M . T B \mathrm{IgG}$ positive reactive result.

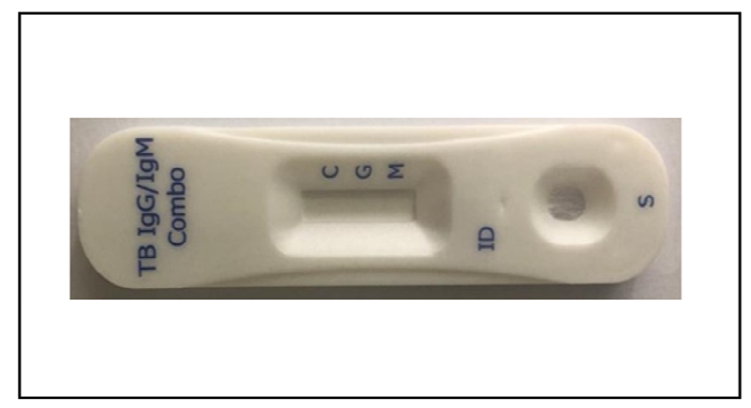

Figure 1. A picture showing Aria TB IgG/IgM combo rapid test kit cassette

\subsubsection{Procedure}

1. The specimen and test components were brought to room temperature $\left(15-30^{\circ} \mathrm{C}\right)$ prior testing.

2. When ready to test, the pouch was opened at the notch and the device was removed. The test device was placed on a clean, flat surface.

3. The device was properly labelled with the specimen's ID number.

4. The plastic dropper was filled with the specimen.

Holding the dropper vertically, 1 drop of serum was dispensed into the sample well, making sure that there is no air and if the specimen does not climb up normally, 1 drop of sample of diluent (buffer) was added to the sample region.

5. The timer was set up and after 15 minutes, the results were read by observing the pink color moves across the Result Window in the center of the cassette.

6. External positive and negative controls supplied by the producer were ran side by side with the test samples.

\subsubsection{Interpretation of Results}

\subsection{Positive Result}

In addition to the presence of the Control " $\mathrm{C}$ " line, if only the IgM " $\mathrm{M}$ " line is developed, the test indicates the presence of IgM anti- $M . T B$ in the serum. In addition to the presence of Control " $C$ " line, if only the IgG " $G$ " line is developed, the test indicates the presence of $\operatorname{IgG}$ anti- $M$. $T B$ in the specimen. Also, in addition to the presence of Control "C" line, if both the "M" and the "G" lines are developed, the test indicates the presence of both IgM and $\operatorname{IgG}$ anti- $M . T B$ in the specimen. The result is positive or reactive.

\subsection{Negative Result}

The absence of any pink color in both the test lines (M and $\mathrm{G}$ ) if only the " $\mathrm{C}$ " line is present, indicates that no anti$M . T B$ antibodies are detected in the specimen. The result is negative or non-reactive.

\subsection{Invalid Result}

The assay is unacceptable regardless of the pink color in the test bands as indicated if no Control "C" line is developed. A complete absence of color in either regions or only one-color band appearing on the test region indicates procedure error and/or the test reagent has deteriorated. If this occurs, the assay was repeated with a new test device. 


\subsection{Data Analysis}

Data from serum antibody tests and questionnaires were entered into Microsoft Excel. The statistical analysis was carried out using SPSS-20.0 (Statistical packages for social scientists, version 20.0). The Two-way Anova Analysis, Turkey-Kramer Multiple Comparisons and Chi-square tests were used to look for significant differences in the prevalence rate of anti-Mycobacterium tuberculosis IgG and IgM antibodies, as well as percentage occurrences of IgG and IgM Mycobacterium TB antibodies. To find significant risk factors connected to $M$. $T B$, we did a simple logistic regression analysis.

\section{Results}

This present study assessed the detection of Mycobacterium tuberculosis IgG and IgM antibodies and associated risk factors among apparently healthy students of Babcock university, Ilishan-Remo Ogun state. Table 1 shows the socio-demographic characteristics of the study participants. Based on age distribution, majority of them were within the age range of 21-25years old (76\%), followed by 16-20years old (24\%). None of the participant belong to the age range 26-30 years and above 30 years. With regards to their marital status, all of the screened participants were single (100\%). They were further stratified according to their study level: 200 level (15\%), 400 Level (52\%), 500 level $(25 \%)$ and 600 level ( $8 \%)$.

100 Level and 300 Level students were not on campus as at the time this study was carried out due to School reopening COVID-19 safety protocol. 86 (86\%) out of the 100 participants practice Christianity, while 14 (14\%) practice Islam. The tribe distribution of the study participants was as follows: Yoruba (70\%), Igbo (13\%), Hausa $(5 \%)$ and others $(12 \%)$. The percentage occurrence of TB IgM and IgG antibodies among the study participants is presented using a bar chart (Figure 2). Out of the 100 study participants screened, only one person (1\%) tested positive for IgM, while $15(15 \%)$ tested positive for IgG.

Table 2 shows the percentage occurrence of TB IgM antibody in relation to the socio-demographic characteristics of the study participants. The only one study participant (1\%) who tested positive to the TB IgM antibody, was a male, belong to the age range: 21-25 yrs, single, 400 Level, Christian and belong to other tribe besides Yoruba, Igbo and Hausa.

Table 1. Socio-demographic characteristics of the study participants.

\begin{tabular}{llll}
\hline Characteristics & Category & Frequency & Percentage \\
\hline Gender & Male & 50 & 50.0 \\
& Female & 50 & 50.0 \\
Age Range & Total & 100 & 100.0 \\
& $16-20$ yrs & 24 & 24.0 \\
& $21-25$ yrs & 76 & 76.0 \\
& $26-30$ yrs & 0 & 0 \\
& $>30$ yrs & 0 & 0 \\
Marital Status & Total & 100 & 100.0 \\
& Single & 100 & 100.0 \\
Study Level & Married & 0 & 0 \\
& Total & 100 & 100.0 \\
& 200 Level & 15 & 15.0 \\
& 400 Level & 52 & 52.0 \\
Religion & 500 Level & 25 & 25.0 \\
& 600 Level & 8 & 8.0 \\
Tribe & Total & 100 & 100.0 \\
& Christianity & 86 & 86.0 \\
& Islam & 14 & 14.0 \\
& Total & 100 & 100.0 \\
& Hausa & 5 & 5.0 \\
& Igbo & 13 & 13.0 \\
& Yoruba & 70 & 70.0 \\
& Others & 12 & 12.0 \\
& Total & 100 & 100.0 \\
\hline
\end{tabular}


Table 2. Percentage Occurrence of TB IgM antibody in relation to the socio-demographic characteristics of the study participants

\begin{tabular}{|c|c|c|c|c|c|c|c|}
\hline Socio-demographic Characteristics & Category & $\begin{array}{l}\text { Number } \\
\text { examined } \\
\mathbf{N}\end{array}$ & $\begin{array}{l}\text { Number } \\
\text { negative } \\
\mathrm{N}\end{array}$ & $\begin{array}{l}\text { Number } \\
\text { positive } \\
\mathbf{N}\end{array}$ & $\begin{array}{l}\text { Pearson } \\
\text { Chi- } \\
\text { Square }\left(\chi^{2}\right)\end{array}$ & $\begin{array}{l}\text { P- } \\
\text { Value }\end{array}$ & $\begin{array}{l}\text { Likelihood } \\
\text { Ratio }\end{array}$ \\
\hline \multirow[t]{3}{*}{ Gender } & Male & 50 & 49 & 1 & 0.426 & 0.551 & 0.573 \\
\hline & Female & 50 & 50 & 0 & & & \\
\hline & Total & 100 & 99 & 1 & & & \\
\hline \multirow[t]{4}{*}{ Age Range } & $16-20 \mathrm{yrs}$ & 24 & 24 & 0 & & & \\
\hline & $21-25 \mathrm{yrs}$ & 76 & 75 & 1 & 0.319 & 0.572 & 0.552 \\
\hline & $26-30 \mathrm{yrs}$ & 0 & 0 & 0 & & & \\
\hline & $>30 \mathrm{yrs}$ & 0 & 0 & 0 & & & \\
\hline \multirow[t]{2}{*}{ Marital Status } & Single & 100 & 99 & 1 & & & \\
\hline & Married & 0 & 0 & 0 & & & \\
\hline \multirow[t]{6}{*}{ Study Level } & 100 Level & 0 & 0 & 0 & & & \\
\hline & 200 Level & 15 & 15 & 0 & & & \\
\hline & 300 Level & 0 & 0 & 0 & & & \\
\hline & 400 Level & 52 & 51 & 1 & 0.932 & 0.818 & 1.317 \\
\hline & 500 Level & 25 & 25 & 0 & & & \\
\hline & 600 Level & 8 & 8 & 0 & & & \\
\hline \multirow[t]{3}{*}{ Religion } & Christianity & 86 & 85 & 1 & 0.164 & 0.685 & 0.303 \\
\hline & Islam & 14 & 14 & 0 & & & \\
\hline & Total & 100 & 99 & 1 & & & \\
\hline \multirow[t]{4}{*}{ Tribe } & Hausa & 5 & 5 & 0 & & & \\
\hline & Igbo & 13 & 13 & 0 & & & \\
\hline & Others & 12 & 11 & 1 & 7.407 & 0.060 & 4.316 \\
\hline & Yoruba & 70 & 70 & 0 & & & \\
\hline
\end{tabular}

Table 3 shows the shows the percentage occurrence of TB IgG antibody in relation to the socio-demographic characteristics of the study participants. Out of the 50 male study participants screened, $9 \%$ were positive to TB IgG, while out of the 50 female study participant screened, $6 \%$ were positive to TB IgG. Still, out of the 24 participants screened under the age range of 16-20 yrs, only 3\% tested positive, while out of the 76 participants screened under the age range of 21-25 yrs, $12 \%$ tested positive to TB IgG. Percentage distribution of TB IgG based on the study level were as follows: 200 level (2\%), 400 level (9\%), 500 level (3\%) 600 level (1\%).Table 4 shows the percentage occurrence of TB IgM antibody among the study participants in relation to clinical signs and symptoms. The only one person (1\%) who tested positive to TB IgM indicated persistent cough, feeling of nausea, night sweats, fever, loss of appetite and constant feeling of fatigue.

Table 3. Percentage Occurrence of TB IgG antibody in relation to the socio-demographic characteristics of the study participants

\begin{tabular}{lccccccc}
\hline $\begin{array}{l}\text { Socio-demographic } \\
\text { characteristics }\end{array}$ & Category & $\begin{array}{c}\text { Number } \\
\text { examined }\end{array}$ & $\begin{array}{c}\text { Number } \\
\text { negative }\end{array}$ & $\begin{array}{c}\text { Number } \\
\text { positive }\end{array}$ & $\begin{array}{c}\text { Pearson Chi- } \\
\text { Square }\left(\chi^{2}\right)\end{array}$ & $\begin{array}{c}\text { P-Value } \\
\text { Likelihood } \\
\text { Ratio }\end{array}$ \\
\hline Gender & Male & 50 & 49 & 9 & 0.178 & 0.659 & 0.566 \\
& Female & 50 & 36 & 6 & & \\
Age Range & Total & 100 & 85 & 15 & & 0.694 & 0.160 \\
& $16-20 \mathrm{yrs}$ & 24 & 21 & 3 & 0.155 & & \\
& $21-25 \mathrm{yrs}$ & 76 & 64 & 12 & & &
\end{tabular}




\begin{tabular}{|c|c|c|c|c|c|c|c|}
\hline & $>30 \mathrm{yrs}$ & 0 & 0 & 0 & & & \\
\hline & Total & 100 & 85 & 15 & & & \\
\hline \multirow[t]{4}{*}{ Marital Status } & Single & 100 & 85 & 15 & & & \\
\hline & Married & 0 & 0 & 0 & & & \\
\hline & Total & 100 & 85 & 15 & & & \\
\hline & 100 Level & 0 & 0 & 0 & & & \\
\hline \multirow[t]{6}{*}{ Study Level } & 200 Level & 15 & 13 & 2 & 0.466 & 0.926 & 0.471 \\
\hline & 300 Level & 0 & 0 & 0 & & & \\
\hline & 400 Level & 52 & 43 & 9 & & & \\
\hline & 500 Level & 25 & 22 & 3 & & & \\
\hline & 600 Level & 8 & 7 & 1 & & & \\
\hline & Total & 100 & 85 & 15 & & & \\
\hline \multirow[t]{3}{*}{ Religion } & Christianity & 86 & 71 & 15 & 2.873 & $0.046^{*}$ & 4.936 \\
\hline & Islam & 14 & 14 & 0 & & & \\
\hline & Total & 100 & 85 & 15 & & & \\
\hline \multirow[t]{5}{*}{ Tribe } & Hausa & 5 & 5 & 0 & 5.059 & 0.168 & 5.244 \\
\hline & Igbo & 13 & 9 & 4 & & & \\
\hline & Yoruba & 70 & 62 & 8 & & & \\
\hline & Others & 12 & 9 & 3 & & & \\
\hline & Total & 100 & 85 & 15 & & & \\
\hline
\end{tabular}

$* \mathrm{P}<0.05$ is considered statistically significant.

Table 5 shows the percentage occurrence of TB $\operatorname{IgG}$ antibody among the study participants in relation to clinical signs and symptoms. None of the 15 study participants who tested positive to TB IgG indicate any of the sign and symptom consistent with TB infection. Table 6 shows the percentage occurrence of TB IgM antibody among the study participants in relation to the risk factors of TB.

Table 4. Percentage occurrence of TB IgM antibody among the study participants in relation to clinical signs and symptoms

\begin{tabular}{|c|c|c|c|c|c|c|c|}
\hline Signs and Symptoms & Category & $\begin{array}{l}\text { Number } \\
\text { examined } \\
\text { N (\%) }\end{array}$ & $\begin{array}{l}\text { Number } \\
\text { negative } \\
\text { N (\%) }\end{array}$ & $\begin{array}{l}\text { Number } \\
\text { positive } \\
\text { N (\%) }\end{array}$ & $\begin{array}{l}\text { Pearson } \\
\left(\chi^{2}\right)\end{array}$ & Chi-Square & $\begin{array}{l}\text { P- } \\
\text { Value }\end{array}$ \\
\hline \multirow[t]{2}{*}{ Persistent Cough } & No & $99(99)$ & $99(99)$ & $0(0)$ & 100.000 & & 0.000 \\
\hline & Yes & $1(1)$ & $0(0)$ & $1(1)$ & & & \\
\hline \multirow[t]{2}{*}{ Chest pain } & No & $99(99)$ & $99(99)$ & $0(0)$ & 100.000 & & 0.000 \\
\hline & Yes & $1(1)$ & $0(0)$ & $1(1)$ & & & \\
\hline \multirow[t]{2}{*}{ Nausea } & No & $99(99)$ & $99(99)$ & $0 \quad(0)$ & 100.000 & & 0.000 \\
\hline & Yes & $1(1)$ & $0(0)$ & $1(1)$ & & & \\
\hline \multirow[t]{2}{*}{ Night sweats } & No & $100(100)$ & $99(99)$ & $1(1)$ & & & \\
\hline & Yes & $0(0)$ & $0(0)$ & $0(0)$ & & & \\
\hline \multirow[t]{2}{*}{ Fever } & No & $99(99)$ & $99(99)$ & $0(0)$ & 100.000 & & 0.000 \\
\hline & Yes & $1(1)$ & $0(0)$ & $1(1)$ & & & \\
\hline \multirow[t]{2}{*}{ Chills } & No & $99(99)$ & $99(99)$ & $0(0)$ & 100.000 & & 0.000 \\
\hline & Yes & $1(1)$ & $0(0)$ & $1(1)$ & & & \\
\hline \multirow[t]{2}{*}{ Loss of appetite } & No & $99(99)$ & $99(99)$ & $0(0)$ & 100.000 & & 0.000 \\
\hline & Yes & $1(1)$ & $0(0)$ & $1(1)$ & & & \\
\hline \multirow[t]{2}{*}{ Fatigue } & No & $99(99)$ & $99(99)$ & $0(0)$ & 100.000 & & 0.000 \\
\hline & Yes & $1(1)$ & $0(0)$ & $1(1)$ & & & \\
\hline
\end{tabular}




\begin{tabular}{lllll} 
Weight loss & No & $100(100)$ & $99(99)$ & $1(1)$ \\
& Yes & $0(0)$ & $0(0)$ & $0(0)$ \\
\hline
\end{tabular}

Table 5: Percentage occurrence of TB IgG antibody among the study participants in relation to clinical signs and symptoms

\begin{tabular}{|c|c|c|c|c|c|c|}
\hline Signs and Symptoms & Category & $\begin{array}{l}\text { Number } \\
\text { examined } \\
\mathbf{N}\end{array}$ & $\begin{array}{l}\text { Number } \\
\text { negative } \\
\mathbf{N}\end{array}$ & $\begin{array}{l}\text { Number } \\
\text { positive } \\
\mathbf{N}\end{array}$ & Pearson Chi-Square $\left(\chi^{2}\right)$ & P-value \\
\hline \multirow[t]{2}{*}{ Persistent Cough } & No & 99 & 84 & 15 & 0.178 & 0.673 \\
\hline & Yes & 1 & 1 & 0 & & \\
\hline \multirow[t]{2}{*}{ Chest pain } & No & 99 & 84 & 15 & 0.178 & 0.673 \\
\hline & Yes & 1 & 1 & 0 & & \\
\hline \multirow[t]{2}{*}{ Nausea } & No & 99 & 84 & 15 & 0.178 & 0.673 \\
\hline & Yes & 1 & 1 & 0 & & \\
\hline \multirow[t]{2}{*}{ Night sweats } & No & 100 & 85 & 15 & & \\
\hline & Yes & 0 & 0 & 0 & & \\
\hline \multirow[t]{2}{*}{ Fever } & No & 99 & 84 & 15 & 0.178 & 0.673 \\
\hline & Yes & 1 & 1 & 0 & & \\
\hline \multirow[t]{2}{*}{ Chills } & No & 99 & 84 & 15 & 0.178 & 0.673 \\
\hline & Yes & 1 & 1 & 0 & & \\
\hline \multirow[t]{2}{*}{ Loss of appetite } & No & 99 & 84 & 15 & 0.178 & 0.673 \\
\hline & Yes & 1 & 1 & 0 & & \\
\hline \multirow[t]{2}{*}{ Fatigue } & No & 99 & 84 & 15 & 0.178 & 0.673 \\
\hline & Yes & 1 & 1 & 0 & & \\
\hline \multirow[t]{2}{*}{ Weight loss } & No & 100 & 85 & 15 & & \\
\hline & Yes & 0 & 0 & 0 & & \\
\hline
\end{tabular}

The only one person who tested positive to TB IgM indicated lack of BCG vaccination, history of TB infection, currently treating TB and diabetes and considered himself not physically fit. Table 7 shows the percentage occurrence of TB IgG antibody among the study participants in relation to the risk factors of TB. Six out of the Seven participants who indicated history of TB tested positive to TB IgG antibody. None indicate history of BCG vaccination, smoking, alcohol consumption, use of social drugs, current TB therapy, current diabetes therapy, history of cancer and positive HIV status. However, all of the 15 participants who tested positive for TB IgG indicated that they were physically fit.

Table 6. Percentage occurrence of TB IgM antibody among the study participants in relation to the risk factors of TB

\begin{tabular}{|c|c|c|c|c|c|c|c|}
\hline Risk Factors & Category & $\begin{array}{l}\text { Number } \\
\text { examined } \\
\mathbf{N}\end{array}$ & $\begin{array}{l}\text { Number } \\
\text { negative } \\
\mathrm{N}\end{array}$ & $\begin{array}{l}\text { Number } \\
\text { positive } \\
\mathbf{N}\end{array}$ & $\begin{array}{l}\text { Pearson } \\
\text { Square }\left(\chi^{2}\right)\end{array}$ & Chi- & $\begin{array}{l}\text { P- } \\
\text { Value }\end{array}$ \\
\hline \multirow[t]{2}{*}{ Do you smoke? } & No & 100 & 99 & 1 & & & \\
\hline & Yes & 0 & 0 & 0 & & & \\
\hline \multirow[t]{2}{*}{ Do you take alcohol? } & No & 100 & 99 & 1 & & & \\
\hline & Yes & 0 & 0 & 0 & & & \\
\hline \multirow[t]{2}{*}{ Do you take social drugs? } & No & 100 & 99 & 1 & & & \\
\hline & Yes & 0 & 0 & 0 & & & \\
\hline \multirow[t]{2}{*}{ Do you have any history of TB? } & No & 93 & 93 & 0 & 13.420 & & 0.000 \\
\hline & Yes & 7 & 6 & 1 & & & \\
\hline \multirow{2}{*}{$\begin{array}{l}\text { Do you have history of BCG } \\
\text { Vaccination }\end{array}$} & No & 100 & 99 & 1 & & & \\
\hline & Yes & 0 & 0 & 0 & & & \\
\hline \multirow[t]{2}{*}{ Are you currently treating TB } & No & 99 & 99 & 0 & 100.000 & & 0.000 \\
\hline & Yes & 1 & 0 & 1 & & & \\
\hline \multirow[t]{2}{*}{ Are you currently treating diabetes? } & No & 99 & 99 & 0 & 100.000 & & 0.000 \\
\hline & Yes & 1 & 0 & 1 & & & \\
\hline
\end{tabular}




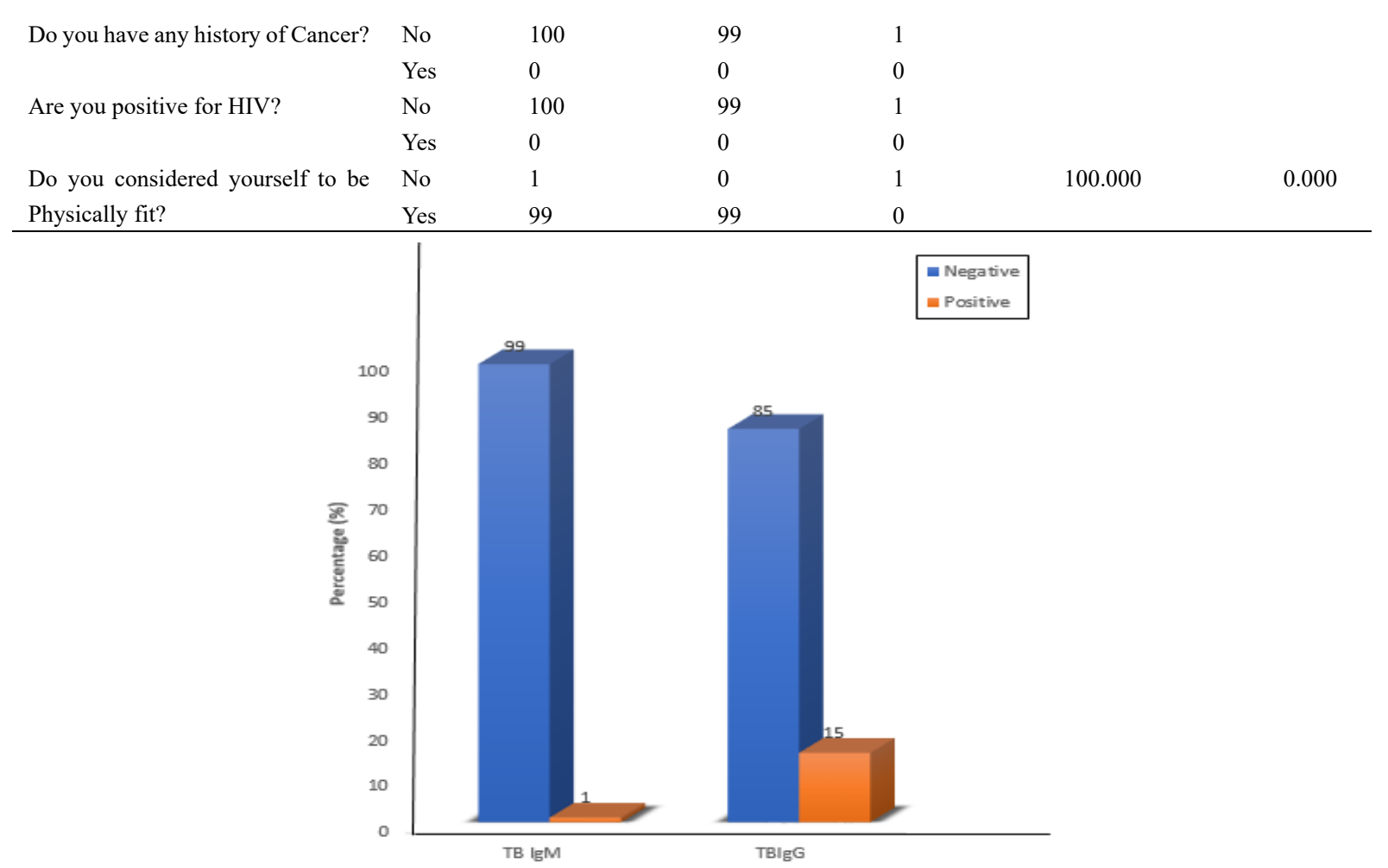

Figure 2. A Histogram showing percentage occurrence of TB IgM and IgG antibodies among the study participants

Table 7. Percentage occurrence of TB IgG antibody among the study participants in relation to the risk factors of TB

\begin{tabular}{|c|c|c|c|c|c|c|}
\hline Risk Factors & Category & $\begin{array}{l}\text { Number } \\
\text { examined } \\
\mathbf{N}\end{array}$ & $\begin{array}{l}\text { Number } \\
\text { negative } \\
\mathrm{N}\end{array}$ & $\begin{array}{l}\text { Number } \\
\text { positive } \\
\mathrm{N}\end{array}$ & Pearson Chi-Square $\left(\chi^{2}\right)$ & P-Value \\
\hline \multirow[t]{2}{*}{ Do you smoke? } & No & 100 & 85 & 15 & & \\
\hline & Yes & 0 & 0 & 0 & & \\
\hline \multirow[t]{2}{*}{ Do you take alcohol? } & No & 100 & 85 & 15 & & \\
\hline & Yes & 0 & 0 & 0 & & \\
\hline \multirow[t]{2}{*}{ Do you take social drugs? } & No & 100 & 85 & 15 & & \\
\hline & Yes & 0 & 0 & 0 & & \\
\hline \multirow[t]{2}{*}{ Do you have any history of TB? } & No & 93 & 84 & 9 & 29.520 & 0.000 \\
\hline & Yes & 7 & 1 & 6 & & \\
\hline Do you have history of BCG & No & 100 & 85 & 15 & & \\
\hline Vaccination & Yes & 0 & 0 & 0 & & \\
\hline \multirow[t]{2}{*}{ Are you currently treating TB } & No & 100 & 85 & 15 & 0.178 & 0.673 \\
\hline & Yes & 0 & 0 & 0 & & \\
\hline \multirow{2}{*}{$\begin{array}{l}\text { Are you currently treating } \\
\text { diabetes? }\end{array}$} & No & 99 & 84 & 15 & 0.178 & 0.673 \\
\hline & Yes & 1 & 1 & 0 & & \\
\hline \multirow{2}{*}{$\begin{array}{l}\text { Do you have any history of } \\
\text { Cancer? }\end{array}$} & No & 100 & 85 & 15 & & \\
\hline & Yes & 0 & 0 & 0 & & \\
\hline \multirow[t]{2}{*}{ Are you positive for HIV? } & No & 100 & 85 & 15 & & \\
\hline & Yes & 0 & 0 & 0 & & \\
\hline \multirow{2}{*}{$\begin{array}{l}\text { Do you considered yourself to } \\
\text { be Physically fit? }\end{array}$} & No & 1 & 1 & 0 & 0.178 & 0.673 \\
\hline & Yes & 99 & 84 & 15 & & \\
\hline
\end{tabular}




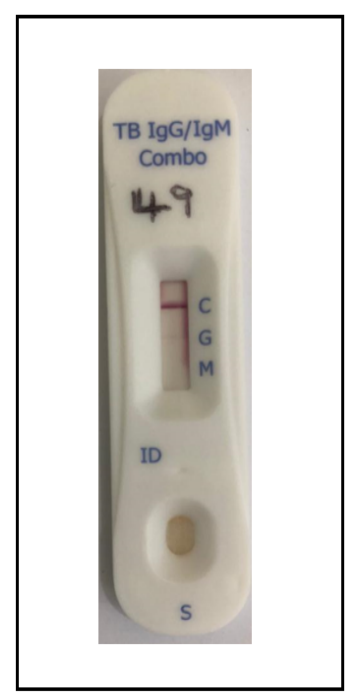

Figure 3. A picture showing Aria TB IgG/IgM combo rapid test kit cassette negative for both TB IgG and IgM antibodies

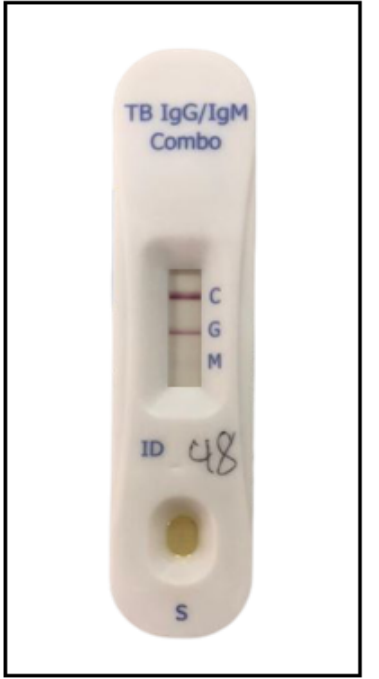

Figure 4. A picture showing Aria TB IgG/IgM combo rapid test kit cassette positive for only TB IgG antibody

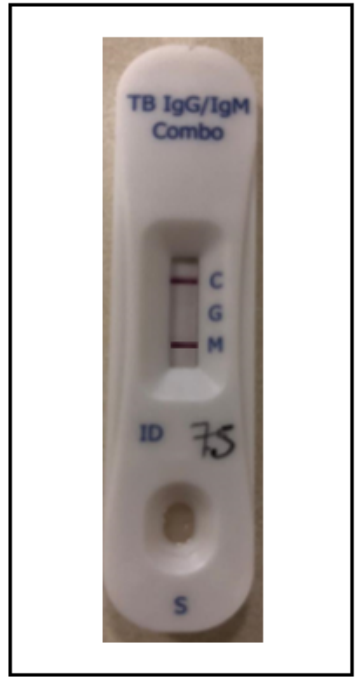

Figure 5. A picture showing Aria TB IgG/IgM combo rapid test kit cassette positive for only TB IgM antibody

\section{Discussion}

Tuberculosis (TB) has been around for millennia and is still a major health concern around the world. It affects around ten million individuals each year and is one of the top ten causes of death globally [7]. According to the WHO Global Report on Mycobacterium tuberculosis [12], Nigeria is one of the 22 nations with the highest TB burden in the world, with more than a quarter million persons developing TB between the ages of adolescence and young adulthood in their creative years. Individuals with diabetes, HIV-positive people, and people who have been diagnosed with cancer are among the high-risk groups for tuberculosis infection in Nigeria, and this comprised the scope of the study. Here in Babcock University, to the best of our knowledge, there is no pre-existing data on the prevalence of Mycobacterium tuberculosis antibodies (IgG and IgM). This study was designed to assess the prevalence of Mycobacterium tuberculosis antibodies (IgG and IgM) among apparently healthy students of Babcock University, Ilishan Remo, Ogun state, Nigeria. A total of 100 study participants were screened using a rapid diagnostic test kit. Among the 100 participants screened in this study, $(15 \%)$ were positive for TB IgG antibody, while only (1\%) person was positive for TB IgM antibody.

The result of this study differs from those of many previous studies. On the one hand, the frequency of occurrence of Mycobacterium tuberculosis IgG antibody in this study is far lower than many other reports on the prevalence of Mycobacterium tuberculosis IgG and IgM antibodies. Devi et al. [13] reported a prevalence of $61 \%$ and $10 \%$ for IgG and IgM, respectively among TB positive patients in India. Similarly, Bam and Karn [14], reported a prevalence of $50 \%$ and $40 \%$ for IgG and IgM respectively, among TB patients in a Teaching Hospital in Nepal, India.

The outcome of this study also differs from that of Wang et al. [15] who reported an IgG prevalence rate of $40.4 \%$, $36.5 \%, 32.7 \%, 70.2 \%$ and $90.4 \%$ among pulmonary TB patients and $0 \%, 2.5 \%, 2.5 \%, 22.2 \%$ and $17.3 \%$ among healthy subjects using five types of TB ELISA kits: Myco G, TB Complex, IBL, Anda-TB and T-SPOT, respectively. The reason for the low prevalence rate reported in this study compared to those of previous studies is likely due to the differences in geographical region, category of study population and the methodology employed for screening.

Furthermore, the results of this study demonstrate that among the seemingly healthy study participants, the lone person who tested positive for TB IgM antibodies was also symptomatic for Mycobacterium tuberculosis infection. Unlike Bam and Karn's [14] study, in which 25 of the 90 patients investigated had tuberculous pleural effusions and 5 had tuberculous lymphadenitis, this study found no tuberculous pleural effusions or lymphadenitis.

Nonetheless, the findings of this study are similar to those of Feng et al. [16], who found a low TB IgM seroprevalence $(29.3 \%)$ compared to a greater TB IgG (36.5\%) among active TB patients in a Beijing hospital. This meant that in a given community, the proportion of people with a history of tuberculosis or previous exposure 
to the disease was higher than the proportion of people who were now infected. The low TB IgM seroprevalence rate recorded in this study could be related to the study participants' healthy lifestyle, which included the absence of characteristics that predispose to TB infection, such as smoking, alcohol use, and the use of social or recreational drugs. This supports the findings of Narasimhan et al. [17] and AL-Khafaji et al. [18]. Furthermore, the 15\% TB IgG antibody detected in this study was found to be lower than the 40.9 percent reported by Chan et al. [19] utilizing an immuno-dot blot assay among active TB patients in Bombay, India. The fact that this study (with apparently healthy patients) had lower TB IgG positive than Chan et al. [19] (with subjects with active TB infection) was not surprising.

In this cross-sectional study, more male participants tested positive to TB IgG antibody (9.0\%) than their female counterparts $(6.0 \%)$. Also, the only person who tested positive for TB IgM antibody was a male. On the one hand, this contradicts the findings of Chinedu et al. [11], who found a significantly (P0.05) higher prevalence of TB antibodies in females $(8.57 \%)$ than in males ( 4.0 percent). The findings of this study, on the other hand, are consistent with those of Feng et al. [16], who used smear and culture methods to find a greater prevalence rate among male patients $(22.1 \%)$ than female patients $(16.4 \%)$. This observation is not unrelated to the fact that feminine genders are more concerned about personal and environmental hygiene than their male counterparts. Another probable explanation is that males can endure a more crowded atmosphere (a risk factor for TB transmission indoors) than females.

Another factor to examine is the age range and category of the study participants in this study; they were all apparently healthy persons between the ages of 16 and 25. This is similar to the findings of Chinedu et al. [11], who found a greater seroprevalence of tuberculosis $(22.2 \%)$ in healthy people aged 20 to 29 . Unlike Feng et al. (2014), all of the participants in this study had active tuberculosis and were between the ages of 19 and 67 . The elderly are more susceptible to tuberculosis infection than young adults. This helps to explain why the prevalence rate in this study was lower than that reported by Feng et al. [16].

Furthermore, on one hand, the outcome of this present study is similar to the work of Acre-Mendoza et al. [20], who reported a prevalence rate of $1.3 \%$ and $17.2 \%$ of TB IgM and IgG antibodies, respectively, among healthy participants in Mexico using indirect ELISA method. These values are very close to the $1 \%$ and $15 \%$, reported for TB IgM and IgG antibodies, respectively, in this current study. On the other hand, it differs from the work of AcreMendoza et al. [20], who reported a prevalence rate of $17.9 \%$ and $8.6 \%$ of TB $\operatorname{IgM}$ and $\operatorname{IgG}$ antibodies, respectively, among individuals with active TB; as well as a prevalence rate of $47.7 \%$ and $20.5 \%$ of TB IgM and IgG antibodies, respectively, among individuals who had contact with those with active TB. The above comparism shows that asymptomatic TB infection may exist and persist in apparently healthy individuals if left undetected and may progress to active and even chronic infection if left untreated.

Close contact with those with active infection offers a major health risk to susceptible individuals, especially those with weakened immune systems, according to Acre-Mendoza et al. [20]. As a result, BCG vaccination is required for susceptible populations such as children and the elderly, as well as those with immunosuppression and underlying diseases (Diabetes, hypertension, liver and kidney disorders).

Antibody production is one of the body's immunological responses to pathogenic organisms such as $M$. tuberculosis. Antibodies to TB have been found in the patient's blood, indicating that he or she has been exposed to the infection. IgM and IgG antibodies are produced by primary (initial month) and secondary (reactivation) immune responses to infectious diseases, respectively. IgM is replaced by $\operatorname{IgG}$ within 2-3 weeks of infection, which lasts longer in the patient's blood and provides long-term immunity. Only TB IgM antibody in a patient's serum indicates that the person is actively infected with tuberculosis, whereas only TB IgG antibody indicates recent or earlier tuberculosis infection. Another explanation for the finding of TB IgG is a history of Bacillus Calmette-Guerin (BCG) vaccination. The presence of both TB IgM and IgG antibodies, on the other hand, indicates both present and prior infection. Meanwhile, the absence of both TB IgM and IgM antibodies suggests that the person is not infected with tuberculosis but is at risk of infection and should take the necessary steps to avoid future exposure.

\section{Conclusion}

The outcome of this study shows that asymptomatic and latent TB infection exist among the study participants and if left undetected and untreated will eventually progress to active tuberculosis with its attending complications including death. This underscores the importance of the ongoing public health education, BCG vaccination, and periodic screening to discover such cases in order to break the infection cycle among the research participants. 


\section{Acknowledgments}

The cooperation of the study participants in sample collection and completion of the questionnaire is highly appreciated.

\section{Disclosure of Conflict of Interest}

All authors declare no form of conflict of interest in this study.

\section{References}

[1] World Health Organization (WHO). (2020). Tuberculosis. Retrieved January 18th 2021, from http://www.who.int/news-room/fact-sheets/detail/tuberculosis

[2] Solomon, B. A., Hannah, B., \& Etefia, E. (2019). The Occurrence of Mycobacterium tuberculosis Among Students Living at The University of Calabar Hostels, Calabar, Nigeria. Mintage Journal of Pharmaceutical and Medical Sciences, 8(4), 14-15.

[3] Cruz, A., \& Starke, J. (2014). Tuberculosis. In Cherry J, HarrisonG, Kaplan S, Steinbach W, Hotez P (ed), Feigin and Cherry's textbook of pediatric infectious diseases. Elsevier Saunders, Philadelphia, PA. p 13351380 .

[4] World Health Organization (WHO). (2010). Global Tuberculosis Control. Retrieved January 18th 2021, from https://apps.who.int/iris/handle/10665/44425

[5] World Health Organization (WHO). (2009). "Epidemiology". Global Tuberculosis Control and Strategy. "WHO/HTM/TB/2009.426". Assessed on the $18^{\text {th }}$ of January, 2021.

[6] World Health Organization (WHO). (2017): Global Tuberculosis Report, www.who.int. Assessed on the $18^{\text {th }}$ of January, 2021.

[7] Dunn, J. J., Starke, J. R., \& Revell, P. A. (2016). Laboratory Diagnosis of Mycobacterium tuberculosis Infection and Disease in Children. J. Clinical Microbiolgy, 54, 1434-1441.

[8] Narasimhan, P., Wood, J., MacIntyre, C. R., \& Mathai, D. (2013). Risk Factors for Tuberculosis, Pulmonary Medicine, 9, 828-939.

[9] Amicocante, M. (2010). Rational use of immunodiagnostic tool for tuberculosis infection: guidelines and cost-effective studies. Journal of the Italian Society for Medical Virology, 33(2), 93-107.

[10] Marie, A. P., \& Niemeier, T. R. (2014). Evaluation of Exposure Tuberculosis among Employees at Medical Center. J. occup. Environ. Hyg., 11(6), 63-68.

[11] Chinedu, A.N., Seema, B., \& Gladys, A. O. (2008). Prevalence of Mycobacterium tuberculosis antibodies in a healthy population in a South-Eastern State of Nigeria. J. Pak Med Assoc., 58(1), 8-10.

[12] World Health Organization (WHO). (2006). Global Tuberculosis control: country profile-Nigeria. pp 107109. Assessed on the $5^{\text {th }}$ of April, 2021.

[13] Devi K. R. U., Ramalingam, B., Brennan, P. J., Narayanan, P. R., \& Raja, A. (2001). Specific and early detection of $\mathrm{IgG}, \mathrm{IgA}$ and $\mathrm{IgM}$ antibodies to Mycobacterium tuberculosis $38 \mathrm{kDa}$ antigen in pulmonary tuberculosis. Tuberculosis, 81(3): 249-253.

[14] Bam, N., \& Karn, R. (2009). IgM and IgG Antibodies in Tuberculosis, Journal of Institute of Medicine, 31(3): 34-36.

[15] Wang, S., Wu, J., Chena, J., Gaoa, Y., Zhanga, S., Zhoub, Z., Huangb, H., Shaoa, L., Jina, J., Zhanga, Y., \& Zhanga, W (2018). Evaluation of Mycobacterium tuberculosis-specific antibody responses for the discrimination of active and latent tuberculosis infection. International Journal of Infectious Diseases, 70 (18): $1-9$.

[16] Feng, X., Yang, X., Xiu, B., Qie, S., Dai, Z., Chen, K., Zhao, P., Zhang, L., ... Zhang, H. (2014). IgG, IgM and IgA antibodies against the novel polyprotein in active tuberculosis. BMC Infectious Diseases, 14(336), $2-9$.

[17] Narasimhan, P., Wood, J., MacIntyre, C. R., \& Mathai, D. (2013). Risk Factors for Tuberculosis, Pulmonary Medicine, 9, 828-939.

[18] AL-Khafaji, J. K. T. (2014). Characterization of Mycobacterium tuberculosis and Predisposing Factors Associated with Tuberculosis Among Risk Population in Baghdad City, Journal of Babylon University/Pure and Applied Sciences, 9(22), 2548. 
[19] Chan, E. D., Reves, R., Belisle, J. T., Brennan, P. J., \& Hahn, W. E. (2000). Diagnosis of Tuberculosis by a Visually Detectable Immunoassay for Lipoarabinomannan. American Journal of Respiratory and Critical Care Medicine, 161, 1713-1719.

[20] Arce-Mendoza, A. Y., Rosas-Taraco, A. G., Cantú Treviño, M. P., Limón-Flores, A. Y., ... Rafael, GonzálezÁlvarez (2018). Efficacy of ELISA test in diagnosis of Mycobacterium tuberculosis infection. Microbiology Research International, 6(10), 20-27.

\section{Copyrights}

Copyright for this article is retained by the author(s), with first publication rights granted to the journal.

This is an open-access article distributed under the terms and conditions of the Creative Commons Attribution license (http://creativecommons.org/licenses/by/4.0/). 